cooling systems of motor-vehicles with cast iron cylinder heads and blocks with the usual assembly of other metals. The mixed inhibitor can also be incorporated in rubber latex, which can then be used to form a protective film on machined parts. A study of boiler-tube corrosion was initiated during the year on behalf of the British Shipbuilding Research Association. Besides work on corrosion-testing technique, the Corrosion Group has continued its study of the low-temperature oxidation of mild steel, and an electron diffraction camera has been installed which should considerably assist the study of surface films on metals. Sets of the apparatus developed in the Laboratory for the speedier testing of protective coatings on surfaces against the effect of atmospheric corrosion have been made by the British Iron and Steel Research Association and distributed to other laboratories for trial.

The functions of the Microbiology Section have been extended to include the maintenance of cultures of industrially important bacteria, with ultimate responsibility for the maintenance of a National Collection of such bacteria. Bacteria previously held at the National Collection of Type Cultures have been taken over; but it was anticipated that it would take until the end of 1950 to examine and catalogue them. The fundamental investigations on the biochemistry of sulphate-reducing bacteria have been intensified, and the competitive inhibition of this reduction by selenate is being applied experimentally by incorporating selenate in protective coatings for ferrous pipes buried in sulphate-bearing clay soils. Biological methods for the control of the nuisance of evil-smelling pools produced by the activities of these bacteria are also being investigated.

Work for the Division of Atomic Energy, Ministry of Supply, on the analysis and concentration of uranium in minerals and ores has continued on an increasing scale, including the development and application of methods, based on solvent extraction in conjunction with the use of cellulose and other solid adsorbents, for preparing and analysing inorganic substances, including uranium products. Other work of the Radiochemical Group on the precipitation of uranium and other metals from solution under controlled conditions has also proved valuable in the development of enrichment processes for uranium from low-grade ores. Besides chemical methods of analysis, this Group has made numerous studies in radioactive methods of analysis, and reports substantial progress in polarographic methods for the direct determination of uranium in solutions containing other metals.

The Inorganic Group, which is now equipped with a Jarrell-Ash grating spectrograph, has successfully completed a semi-scale trial of its method for extracting germanium and gallium from flue dust by fusion with caustic soda and obtained an 80 per cent overall yield. A new investigation on the conversion of phosphate rock into forms of fertilizer which are easily assimilated by plants and in which less sulphuric acid is required has yielded promising results in preliminary work with mixtures of nitric and sulphuric acid. In chromatography, a method has been developed for the quantitative separation of nickel, manganese, cobalt, copper and iron in solution as chlorides on paper strips, and the method for nickel, cobalt, copper and iron has been extended to separations on cellulose columns. Much of the work of the Spectroscopic Laboratory has been concerned with the quantitative examination of products derived from eluates obtained in this work with cellulose columns.

A prominent part of the work of the Organic Group is now the determination of accurate physical and physico-chemical data for pure organic compounds, and besides informal discussions between the Director of the Chemical Research Laboratory and Prof. D. M. Newitt, the Superintendent of the Physics Division of the National Physical Laboratory, to co-ordinate work in this field, there has been cooperation with the Hydrocarbon Research Group of the Institute of Petroleum. In consequence, the Laboratory has undertaken responsibility for procuring and distributing a range of standard pure hydrocarbons required for calibrating mass-spectrometers and other purposes. The Purification and Measurements Section has developed methods for the purification of $\beta$ - and $\gamma$-picoline and $2: 6$-lutidine and also new thermodynamic tests for vapour-liquid equilibrium data in ternary systems. An apparatus has been designed for the automatic recording of freezing-point curves, and a method worked out for the determination of 4-methyl-2:6-di-tertiary-butylphenol in industrial mixture by infra-red absorption spectroscopy, as well as for the determination of small quantities of water in pyridine homologues. In the Organic Intermediates Section, progress is reported in identifying and synthesizing insecticidal compounds contained in the piperidine- and other nitrogen-containing fractions. Two homologous series of $\mathrm{N}$-substituted piperidines are being synthesized for evaluation, and further work has been done on the hydrogenation of diphenylene oxide and $o$-diphenol, as well as on the polymers and co-polymers of acenaphthylene. A considerable amount of effort has been given to the synthesis of carbon-13 labelled intermediates from enriched potassium cyanide, and progress is reported in the elaboration of adequate methods for intermediates. A number of polyfunctional halides and bases have been prepared for the synthesis of ion-exchange resins, and to obtain a non-polar lubrication standard the hydrocarbon, docosane, was synthesized from lauric acid.

\section{GOVERNMENT EXPENDITURE IN THE WELFARE STATE}

$\mathrm{R}$ ECENT reports from the Committee on Public Accounts have indicated that the mounting scale of expenditure on the universities and similar institutions and on the Department of Scientific and Industrial Research is leading to requests for closer public accountability of such expenditure, even by those who are most concerned to safeguard the independence of the universities and who are alive to the danger of cramping research activities by petty restrictions. Possibly the spirit of such requests may be satisfied by a greater disposition on the part. of these organizations to recognize that full publication of results as early as possible is a return which the nation is entitled to expect, as indeed was pointed out by one speaker at the British Association meeting in Birmingham; but it is clear from two recent broadsheets issued by Political and Economic Planning that there is a real danger, and that some new means of accountability may have to be devised to satisfy the nation that there is no excessive waste and that a reasonable return is being secured. 
The first of these broadsheets, No. 317, dealing with government spending, makes it clear that pressure to this end is likely to arise out of the acute problem of adapting the British economy to a big increase in defence expenditure. The broadsheet, it is true, is concerned chiefly with examining the nature of government spending and its effects with the view of determining whether it is true that no reduction in government expenditure can be made without doing more harm than good, or whether, on the contrary, a high rate of government spending is a drag on economic progress and a hindrance to the long-term solution of the foreign trade problem.

The survey indicates some of the consequences of the Government's need for balancing the claims of defence against those of other economic activities and to decide such questions as the rate of house-building or the amount to be spent on hospitals. The Government, it is pointed out, has only a limited control over some parts of the economy. It must accept that increased spending by public authorities will probably be at the expense of the provision of industrial equipment rather than of consumption. The welfare State involves a high level of taxation to cover large spending by public authorities and large monetary transfers. This tends to diminish the traditional incentive to effort and, in the absence of new ones, to check production. This danger may impose limits on what the Government can do with safety.

The most important conclusion reached here by Political and Economic Planning is that, while the dependence of decisions on policy to some extent on personal judgment is admitted, with consequent room for dispute, the area of dispute could be reduced if more facts and figures were available. Planning decisions must be based on a knowledge of the relevant facts, so far as they can be ascertained. It is true that the total effects of a tax, or of taxation as a whole, cannot be assessed with any degree of accuracy ; but at present the planning authorities lack knowledge of ascertainable facts. The figures on government spending are not available in the most illuminating form.

A new elassification of government spending may be desirable, and P E P argues convincingly that a more illuminating presentation of the facts about government spending would confer economic benefits by leading to a better organization of the economy. Since the official statisticians of the Treasury and the Cabinet Office do not appear to have supplied the Government with all the ascertainable facts about the activity which is most directly under its control, the broadsheet suggests that the official statisticians should share the work with such bodies as the Oxford University Institute of Statistics and the Department of Applied Economics at Cambridge. The lead must come from the Civil Service, since the first step is the remodelling of the system of accounting and recording in the various departments. If the raw material were thus improved, there is little doubt that the Treasury and the Cabinet Office would receive plenty of outside help in the new research which would be made possible.

The second of these broadsheets, No. 318, dealing with government and industry, goes further into the doctrine of public accountability, but mainly from the point of view of the relationship of the Government to industry in the so-called 'mixed economy' which Britain has now come to be. It attempts to trace the shape of that relationship as it was developing from the full control of the War and its immediate aftermath to a more liberal system. The broadsheet assumes that the place of the Government in that relationship will continue to be larger than in days gone by, whatever political party holds the power. Some of the fundamental questions which have to be faced in the relations of Government to industry are well summarized in the second broadsheet. The first is the fundamental political dilemma of peace-time: Is Government intervention in industry on the present scale necessary ? Further, if there is a need, is the present mixed system--'voluntarism', with a background of control -the right one in principle? Does the system as it operates to-day create the best possible psychological atmosphere? What is its effect on costs, to the firm and to the community? Lastly, in the system as it has developed, is the consumer adequately protected ?

\section{SCIENTIFIC COUNCIL FOR AFRICA}

ARLY in 1951 the Scientific Council for Africa South of the Sahara held its first session in Nairobi under the chairmanship of Dr. P. J. du Toit of South Africa, and was attended by Prof. J. Millot (Madagascar), Dr. F. J. Cambournac (Portugal), Sir Alexander Carr-Saunders (United Kingdom), Dr. B. A. Keen (British East Africa), Dr. A. Mendes Correa (Portugal), Prof. T. Monod (French West Africa), Col. H. W. Mulligan (Nigeria), Dr. B. F. J. Schonland (South Africa), Mr. N. P. Sellick (Southern Rhodesia), Dr. Georges J. Bone (Belgian Congo) and Prof. Trochain (French Equatorial Africa)*.

Being the inaugural meeting, the Council was chiefly concerned with problems of organization and method. It proved possible, however, to devote considerable attention to examination of the fiftythree resolutions on scientific collaboration in Africa adopted at the African Regional Scientific Conference in Johannesburg in 1950. These resolutions were thoroughly sifted, and priorities were allocated to assist the Council and governmental and other authorities concerned in carrying out these recom. mendations. Among the proposals which the Council decided should be examined in detail as a first priority were the following : the establishment of an Inter-African Regional Bureau on Geology; the achievement of cartographic uniformity in the maps of Africa, and the preparation of special regional maps dealing with such subjects as geology, climatology, vegetation, vector-borne diseases, etc.; the extension of co-ordinated development in the field of hydrology and water conservation; the calling of a specialist meeting on housing and building research; and the co-ordination of scientific library and bibliography services.

It was reported that considerable progress had already been made in carrying out a number of the Johannesburg Conference proposals. Arrangements were made for the appointment of honorary regional consultants and correspondents in Africa representing all the main scientific disciplines.

To avoid duplication and overlapping of functions with those undertaken by other organizations, careful attention was given to the recommendations of the several African scientific conferences which have been held in the past few years on such specialized subjects as trypanosomiasis, rinderpest and soil conservation.

* South African J. Sci., 6, January 1951. 